\title{
CAN HIGH-RISK OLDER DRIVERS BE IDENTIFIED IN A DMV SETTING WITH A BRIEF BATTERY OF FUNCTIONAL TESTS?
}

\author{
Karlene Ball ${ }^{1}$, Daniel Roenker ${ }^{2}$, Gerald McGwin, Jr. ${ }^{1}$, \\ Virginia Wadley ${ }^{1}$, Jeff Edwards ${ }^{1}$, R. Raleigh ${ }^{3}$ \\ ${ }^{1}$ University of Alabama at Birmingham \\ 100 Holley Mears \\ 924 19th Street South \\ Birmingham, AL 35294-2100 \\ ${ }^{2}$ Western Kentucky University \\ ${ }^{3}$ Maryland Motor Vehicle Administration \\ E-mail: kball@uab.edu
}

\begin{abstract}
Recent research has indicated that some laboratory measures of functional ability may discriminate between crash-involved and crash-free older adults. However, the ability of these tests to provide the same level of discriminability in a real-world setting such as a Department of Motor Vehicles remains to be established. Therefore, in conjunction with the Maryland Department of Motor Vehicles and the National Highway Traffic Safety Administration, a brief battery of tests was developed and evaluated. The battery contained a number of cognitive tests (e.g., UFOV ${ }^{\circledR}$ subtest 2, the closure subtest of the Motor Free Visual Perception Test [MVPT], Trails A and B, etc.) and physical measures (e.g., Rapid Pace Walk, Head and Neck Rotation, etc.) that prior literature had indicated might be related to crash risk in older adults. Motor Vehicle Administration staff were trained to administer the test battery. Older adults $(\mathrm{N}=4,173$, mean age $=69$ years) were approached by the staff after license renewal and asked to help evaluate the brief battery. Of the 4,173 older adults approached at the field sites, 2,112 individuals aged 55-96 years of age participated. The primary outcome of interest for this study was the occurrence of an at-fault Motor Vehicle Collision (MVC) following assessment. For members of this sample, the outcome period ranged from 2-3 years. Rate Ratios were determined for each functional variable based upon at-fault crashes adjusted for driving exposure over this period. Univariate analyses revealed that five variables (Age, Walk Time, MVPT, Trails A and $\mathrm{UFOV}^{\circledR}$ ) were significantly related to crash frequency. These significant variables overlapped with one another to a certain degree, indicating that impaired older drivers score poorly on multiple cognitive assessments. The UFOV ${ }^{\circledR}$ subtest 2 appears to be the most strongly associated within this analysis $(\mathrm{RR}=3.78, \mathrm{p}<.05)$. When each variable in the model was adjusted for every other variable, only $\mathrm{UFOV}^{\circledR}(\mathrm{RR}=2.41, \mathrm{p}<.05)$ and Rapid Pace Walk $(R R=1.96, \mathrm{p}<.05)$ remained uniquely related to the frequency of state-reported, at-fault crashes. The role of such a screening battery in field settings such as a DMV will be discussed.
\end{abstract}

